\title{
Investigation on protective effects of Cressa cretica extract in scopolamine- induced memory impairment
}

\author{
Pragati Khare*, Ghanshyam Yadav, Sudhir Chaudhary , Lubhan Singh \\ Department of Pharmaceutical Technology, Meerut Institute of Engineering and Technology \\ *Corresponding author E-mail: pragatikhare10@gmail.com
}

\begin{abstract}
The present study was undertaken to investigate the effects of Cressa cretica on learning and memory in mice. Elevated plus maze and passive avoidance paradigm were utilized to test learning and memory. Two doses (200 and $400 \mathrm{mg} / \mathrm{kg}$, p.o.) of ethanolic extract were administered for 28 successive days in separate group of animals. The dose of 400-mg/kg p.o. of CCE (Cressa cretica extract) significantly improved learning and memory of mice. Furthermore, this dose significantly reversed the amnesia induced by Scopolamine $(0.4$ $\mathrm{mg} / \mathrm{kg}$, i.p.). To find out the mechanism by which CCE exerts nootropic activity, the effect of CCE on whole brain AChE activity was also estimated. CCE also decreased whole brain acetyl cholinesterase activity. Antioxidant properties and presence of flavonoids in Cressa cretica may be contributing to memory enhancement effect. Here, Piracetam ( $200 \mathrm{mg} / \mathrm{kg}$, i.p) was used as a standard nootropic agent. Hence Cressa cretica appears to be a promising candidate for improving memory and it would be worthwhile to explore the potential of this plant in the management of dementia and Alzheimer's disease. However, further studies are necessitated to identify the exact mechanism of action.
\end{abstract}

Keywords: Cressa cretica, Alzheimer's disease, Central nervous system (CNS), Elevated plus maze, Passive avoidance apparatus .

\section{Introduction}

Aging is an unavoidable process in which a variety of progressive physiological and pathological changes are involved. There is marked decline in learning and memory abilities in the course of normal aging. CNS is highly susceptible to damage by free radicals. The excessive production of free radicals in aged brain can attack and deteriorate many different cellular components including membrane lipids, proteins and DNA, thereby causing neuron damage and dysfunction. The cholinergic hypothesis of geriatric memory dysfunction which suggested that the reduction of cholinergic neurotransmission i.e. the level of Acetylcholine decreases in brain which is a critical component for the memory deficits associated with aging has been widely accepted (Xu et al. 2009). Dementia is a mental disorder which is characterized by loss of intellectual ability sufficiently severe as to interfere with one's occupational or social activities. The most common cause of dementia is Alzheimer's disease (AD), which is a progressive neurodegenerative disorder associated with loss of neurons in distinct brain areas (Dhingra et al. 2004). AD is characterized by the presence of excessive amounts of neurotic plaques containing amyloid $\beta$ protein and loss of cholinergic markers in brain. Loss of cholinergic cells particularly in the basal forebrain is accompanied by loss of the neurotransmitter acetylcholine. A decrease in acetylcholine in the brain of patients with $\mathrm{AD}$ appears to be responsible for producing dementia (Kulkarni et al. 2011). One of the major markers of cholinergic function is the activity of the enzyme acetylcholinesterase (AChE) which is known to be decreased with aging in various cerebral areas and synaptic plasma membranes. AChE activity is also known to be decreased by free radicals and increased oxidative stress. Various antioxidant supplements and phytochemical components might be helpful for preserving brain functions and forestalling the age-related deficits (Papandreoua et al. 2011).

Cressa cretica L. belongs to the Convolvulaceae family is a remarkable salt tolerant plant, common in coastal areas (Sunita et al. 2009). It is known as Rudanti in indigenous system of medicine in India and Molleih or Nadewa in Arabic. It is reported to be antibilious, antitubercular, antibacterial, antiviral, antidiabetic and expectorant (Sunita et al. 2011). The plant is used as alterative, anthelmintic, stomachic, and tonic, aphrodisiac, enriches the blood and is useful in constipation, leprosy, asthma and urinary discharges. The plant is traditionally used in Bahrain as expectorant and antibilious agent (Priyashree et al. 2012, Rani et al. 2011). According to few reports, the isolation of coumarins, sterols and quercetin glycosides with unidentified sugars and high salt content has been done. (Chaudhary et al. 2012, Chaudhary et al. 2010, Gupta et al. 2006). Phytochemical screening of the plant growing in Qatar revealed the presence of alkaloids, flavonoids, coumarins and sterols (Chaudhary et al. 2012).

\subsection{Geographical source}

Cressa cretica is a remarkable salt tolerant plant, common in coastal areas usually occurring in marshes. This plant is distributed throughout India, Timor, and Australia (Rani et al. 2011, Shahat et al. 2005, Suganthi et al. 2008).

\section{Materials and methods}

\subsection{Plant material}


The plant of Cressa cretica was collected from the sandy shores along the mangrove creeks near Devanampattinam Beach, Cuddalore district in Tamilnadu and authenticated (specimen number- 74052) by taxonomist Dr. K.Ravikumar FRLHT Bangalore. A voucher specimen of collected sample was deposited in the institutional herbarium for future reference.

\subsection{Preparation of extracts}

The plant of Cressa cretica was washed thoroughly in tap water shade dried and powdered. This powder was packed into Soxhlet column and extracted with petroleum ether $\left(60-80^{\circ} \mathrm{C}\right)$ for $24 \mathrm{~h}$. The same marc was successively extracted with chloroform (50 $\left.60^{\circ} \mathrm{C}\right)$ and later with ethanol $\left(68-78^{\circ} \mathrm{C}\right)$ for $24 \mathrm{~h}$. The extracts were concentrated on water bath $\left(50^{\circ} \mathrm{C}\right)$. After concentrated preparation, the dried powder extract was stored at room temperature. The yield of the petroleum extract, chloroform extract and ethanolic extract were found to be $0.8 \%(\mathrm{w} / \mathrm{w}), 0.8 \%(\mathrm{w} / \mathrm{w})$ and $1.0 \%(\mathrm{w} / \mathrm{w})$ respectively. Ethanolic extract was used for the experimental study.

\subsection{Drug treatment}

For the pharmacological tests, the obtained extract was suspended in double distilled water containing carboxy methyl cellulose (1\%w/v CMC) in doses of $200,400-\mathrm{mg} / \mathrm{kg}$ p.o. The doses were fixed based on earlier studies on the ethanolic extract of Cressa cretica extract (CCE) were administered to individual mice in-group $4,5,7,8$. There was no mortality due to treatment up to end of the observation period. The Cressa cretica drug extract caused no abnormality or death during the course of treatment.

\subsection{Animals}

Animals were procured from Central Animal House, Department of Pharmaceutical Technology, MIET, and Meerut. Animals were approved by Institutional Animal Ethic Committee (IAEC) of Department of Pharmaceutical Technology, MIET, and Meerut. Approval number (711/02/a/CPCSEA/2011-12/14) was given for this work. The preferred rodent species included mice. Swiss albino strains of young healthy adult of either sex animals in equal numbers per group $(n=6)$ were taken. At the commencement of the study the weight variations of animals used was kept minimal and not exceeded $\pm 20 \%$ of the mean weight of each animal. Normal weight of mice was $25-30 \mathrm{gm}$.

The temperature of the experimental animal room was maintained to be $22^{\circ} \mathrm{C}\left( \pm 3^{\circ} \mathrm{C}\right)$. Relative humidity was maintained between 50 $60 \%$. Lighting was artificial, the sequence being 12 hours light, 12 hours dark. For feeding, conventional laboratory diets were used with drinking aqueous supplied ad libitum. Animals of same group were caged together. Healthy young adult of either sex mice were randomly assigned to the control, standard and treatment groups. The animals were identified uniquely (i.e., via marking at the base of the tail) and acclimatized for not less than 5 days in their cages prior to the start of the study.

\subsection{Drugs and chemicals}

Drugs: Piracetam and Scopolamine were purchased from Sigma Aldrich.

Chemicals: Petroleum ether, Ethyl Acetate, Ethanol, Chloroform, Methanol, were purchased from Central Drug House Laboratory (CDH).

\subsection{Vehicle}

The plant extract (CCE) was suspended in 1\%w/v CMC and administered orally in mice. Scopolamine hydrobromide and Piracetam were dissolved separately in normal saline and injected i.p. Volume of oral administration and i.p. injection was $1 \mathrm{ml} / 100$ $\mathrm{g}$ of mouse.

\section{Exteroceptive behavioral models}

\subsection{Elevated plus maze}

The elevated plus maze served as the exteroceptive behavioral model (wherein the stimulus existed outside the body) to evaluate learning and memory in mice. The apparatus consisted of two open arms $(16 \mathrm{~cm} \times 5 \mathrm{~cm})$ and two covered arms $(16 \mathrm{~cm} \times 5 \mathrm{~cm}$ $\times 12 \mathrm{~cm})$. The arms extended from a central platform $(5 \mathrm{~cm} \times 5 \mathrm{~cm})$ and the maze was elevated to a height of $25 \mathrm{~cm}$ from the floor. On the first the day, each mouse was placed at the end of open arm, facing away from central platform. Transfer latency (TL) was taken as the time taken by the mouse to move into any one of the covered arms with all its four legs. TL was recorded on the first day for the each animal. The mouse was allowed to explore the maze for another $2 \mathrm{~min}$. and returned to its home cage. Retention of this learned task was examined $24 \mathrm{~h}$ after the first day trial.

Mice were divided into 8 groups and each group consisted of a minimum of 6 animals separate animals were used for each experiment.

Table 1: Experimental Design

\begin{tabular}{|c|c|c|}
\hline Group & Treatment & Dose $(\mathrm{mg} / \mathrm{kg})$ \\
\hline 1 & $\begin{array}{l}\text { Normal control treated with vehi- } \\
\text { cle }\end{array}$ & \\
\hline 2 & $\begin{array}{l}\text { Positive group treated with } \\
\text { Piracetam }\end{array}$ & $200 \mathrm{mg} / \mathrm{kg}$, i.p \\
\hline 3 & $\begin{array}{l}\text { Negative control treated with sco- } \\
\text { polamine }\end{array}$ & $0.4 \mathrm{mg} / \mathrm{kg}$, i.p \\
\hline 4 & Extract low dose & $200 \mathrm{mg} / \mathrm{kg}$, p.o. \\
\hline 5 & Extract high dose & 400mg/kg, p.o. \\
\hline 6 & Positive control + Scopolamine & $\begin{array}{l}200 \mathrm{mg} / \mathrm{kg}+0.4 \mathrm{mg} / \mathrm{kg} \text {, } \\
\text { i.p }\end{array}$ \\
\hline 7 & Extract low dose + Scopolamine & $\begin{array}{l}200 \mathrm{mg} / \mathrm{kg} \text {, p.o.+ } \\
0.4 \mathrm{mg} / \mathrm{kg} \text {, i.p }\end{array}$ \\
\hline 8 & Extract high dose + Scopolamine & $\begin{array}{l}400 \mathrm{mg} / \mathrm{kg}, \text { p.o.+ } \\
0.4 \mathrm{mg} / \mathrm{kg} \text {, i.p }\end{array}$ \\
\hline
\end{tabular}

Group I: It represented the control group for young mice. Vehicle was administered orally for 28 successive days and transfer latency was measured after 90 min of administration on 28th and again after 24 hr i.e. on 29th day.

Group II: It represented the positive control group for young mice. Piracetam $(200 \mathrm{mg} / \mathrm{kg}$ i.p.) was injected to young mice for 28 successive days and transfer latency was measured after $60 \mathrm{~min}$ of administration on 28th day and again after $24 \mathrm{hr}$ i.e. on 29th day.

Group III: It represented the negative control group for young mice. Scopolamine $(0.4 \mathrm{mg} / \mathrm{kg})$ was injected i.p. to young mice and transfer latency was measured $45 \mathrm{~min}$ after injection and again after $24 \mathrm{hr}$ (i.e. on 29th day).

Group IV and V: CCE $(200,400 \mathrm{mg} / \mathrm{kg}$, p.o.) were administered orally to the young mice for 28 successive days. TL was noted after $90 \mathrm{~min}$ of administration on 28th day and again after $24 \mathrm{hr}$ i.e. on 29 th day.

Group VI: Piracetam $(200 \mathrm{mg} / \mathrm{kg}$, i.p. $)$ was injected for 28 successive days to young mice. At $60 \mathrm{~min}$ after the injection of piracetam on the 28th day, scopolamine $0.4 \mathrm{mg} / \mathrm{kg}$, i.p. was administered. TL was noted after 45 min of administration of scopolamine and again after $24 \mathrm{hr}$ i.e. on 29 th day.

Group VII, VIII: CCE $(200,400$ mg/kg, p.o.) were administered orally to the young mice for 28 successive days and Scopolamine $(0.4 \mathrm{mg} / \mathrm{kg})$ was injected i.p. to young mice at $90 \mathrm{~min}$. after administration of extract on 28th day. TL was noted $45 \mathrm{~min}$. after injection and after $24 \mathrm{~h}$ (i.e. on 29th day).

\subsection{Passive avoidance paradigm}

Passive avoidance behavior based on negative reinforcement was used to examine the long-term memory. The apparatus consisted of a box $(27 \mathrm{~cm} \times 27 \mathrm{~cm} \times 27 \mathrm{~cm})$ having three walls of wood and one wall of Plexiglas, featuring a grid floor (made up of $3 \mathrm{~mm}$ stainless steel rods set $8 \mathrm{~mm}$ apart), with the wooden platform (10 
$\mathrm{cm} \times 7 \mathrm{~cm} \times 1.7 \mathrm{~cm}$ ) in the center of the grid floor. The box was illuminated with a $15 \mathrm{~W}$ bulb during experimental period. Electric shock $(20 \mathrm{~V}, \mathrm{AC})$ was delivered to the grid floor. Training was carried out in two similar sessions. Each mouse was gently placed on the wooden platform set in the center of grid floor. When the mouse stepped down placing all its paws on the grid floor, shocks were delivered for $15 \mathrm{sec}$ and step-down latency (SDL) was recorded. SDL was defined as the time (in seconds) taken by the mouse to step down from the wooden platform to grid floor with all its paws on the grid floor. Animals showing SDL in the range of 2-15 s during the first test were used for the second session and the retention test. The second session was carried out $90 \mathrm{~min}$. after the first test. When the animals stepped down before $60 \mathrm{~s}$, electrical shocks were delivered for $15 \mathrm{sec}$. During the second test, animals were removed from shock free zone, if they did not step down for a period of $60 \mathrm{~s}$. Retention was tested after $24 \mathrm{~h}$ in a similar manner, expect that the electric shocks were not applied to the grid floor observing an upper cut-off time of 300s.

Mice were divided into 15 groups and each group consisted of a minimum of 6 animals. Separate animals were used for each experiment

Group I: It represented the control group for young mice. Vehicle was administered orally for 28 successive days. Shock was delivered for 15 seconds after 90 minutes of vehicle administration on the day 28 and SDL was noted after $24 \mathrm{~h}$ (i.e. on 29th day).

Group II: It represented the positive control group for young mice. Piracetam (200 mg/kg i.p.) was injected to young mice for 28 successive days. Shock was delivered for 15 secs after 60 mins of i.p. injection on the day 28 and SDL was noted after 24 h (i.e. on 29th day).

Group III: It represented the negative control group for young mice. Scopolamine $(0.4 \mathrm{mg} / \mathrm{kg})$ was injected i.p. to young mice and transfer latency was measured $45 \mathrm{~min}$ after injection and again after $24 \mathrm{hr}$ (i.e. on 29th day.).

Group IV and V: CCE $(200,400 \mathrm{mg} / \mathrm{kg}$, p.o.) were administered orally to the young mice for 28 successive days to young mice. Shock was delivered for 15 secs after 90 mins of extract administration on the day 28 and SDL was noted after 24 h (i.e. on 29th day).

Group VI: Piracetam $(200 \mathrm{mg} / \mathrm{kg}$, i.p. $)$ was injected for $28 \mathrm{suc}$ cessive days to young mice. At $60 \mathrm{~min}$ after the injection of piracetam on the seventh day, scopolamine $0.4 \mathrm{mg} / \mathrm{kg}$, i.p. was administered. Shock was delivered for 15 secs after 90 mins of extract administration on the day 28 and SDL was noted after $24 \mathrm{~h}$ (i.e. on 29th day).

Group VII and VIII: CCE (200, $400 \mathrm{mg} / \mathrm{kg}$, p.o.) were administered orally to the young mice for 28 successive days and Scopolamine $(0.4 \mathrm{mg} / \mathrm{kg})$ was injected i.p.to young mice at $90 \mathrm{~min}$. after administration of extract on day 28. TL was noted $45 \mathrm{~min}$. after injection and after $24 \mathrm{hr}$ (i.e. on 29 th day).

\subsection{Estimation of Brain $\mathrm{AChE}$ activity}

The time frame of cholinesterase activity estimation was similar to the behavioral tests i.e.8am $-11 \mathrm{am}$ on each day. On the 30th day animals were euthanized by cervical dislocation carefully to avoid any injury to tissues. The whole brain AChE activity was measured using the Ellman's method. The end point was the formation of the yellow color because of the reaction of thiocholine with dithiobisnitrobenzoate ions. The rate of formation of thiocholine from acetylcholine iodide in the presence of tissue cholinesterase was measured using spectrophotometer. The resulting yellow color is due to reduction of DTNB by certain substances in the brain homogenate and due to non-enzymatic hydrolysis of substrate. After having calibrated the instrument, change in absorbance per min of sample was read at $420 \mathrm{~nm}$.

Rate $=\frac{\text { Change in the absorbance } / \min }{\text { Co }} \times\left(5.74 \times 10^{-4}\right)$

Where,

Rate $=$ Moles substrate hydrolyzed per min per gram of tissue
$\mathrm{Co}=$ Original concentration of brain tissue $(\mathrm{mg} / \mathrm{ml})$

\subsection{Statistical analysis}

All the results were expressed as mean \pm standard error (SEM). Data were analyzed using one-way ANOVA followed by Dunnett's test. $p<0.001$ and $p<0.05$ were considered as statistically significant.

\section{Results}

\subsection{Effect on transfer latency (by Elevated Plus Maze)}

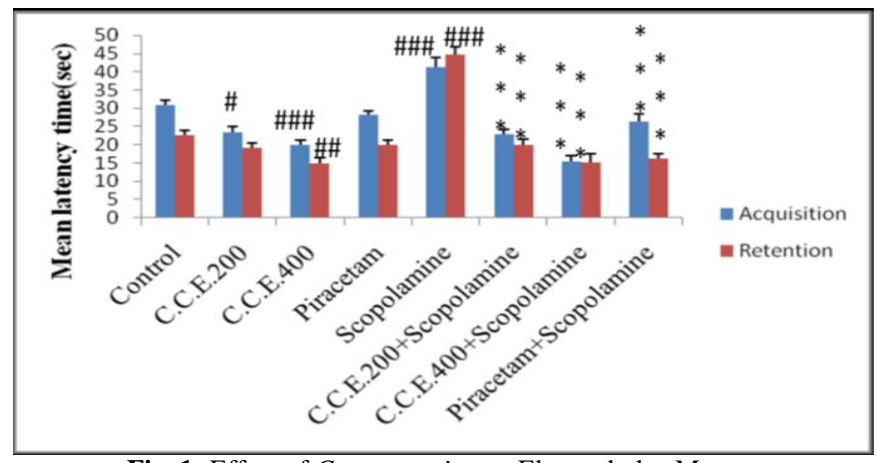

Fig. 1: Effect of Cressa cretica on Elevated plus Maze

Results were expressed as MEAN \pm S.E.M., $\mathrm{n}=6$ and analyzed by one-way ANOVA followed by Dunnett's test. \# P $<0.05$, \#\# $<0.01$, \#\#\# p < 0.001 when group compared with control group. $* * * p<0.001$, when groups compared with Scopolamine group.

Transfer latency (TL) of first day reflected learning behavior of animals whereas, TL of second day reflected retention of information or memory. Cressa cretica (200 and $400 \mathrm{mg} / \mathrm{kg}$ ) and Piracetam $(200 \mathrm{mg} / \mathrm{kg})$ administration for 28 successive days orally, intra-peritoneally respectively, significantly decreased TL on first day as well as second days, indicating significant improvement of learning and memory. Scopolamine $(0.4 \mathrm{mg} / \mathrm{kg})$ injected before training impaired learning significantly as indicated by increased TL. Ethanolic extract of Cressa cretica (200 and 400 $\mathrm{mg} / \mathrm{kg}$ ) and Piracetam $(200 \mathrm{mg} / \mathrm{kg}$ ) administered orally for 28 days protected the animals from scopolamine-induced impairment in learning and memory.

\subsection{Effect on transfer latency (by Passive Avoidance Apparatus)}

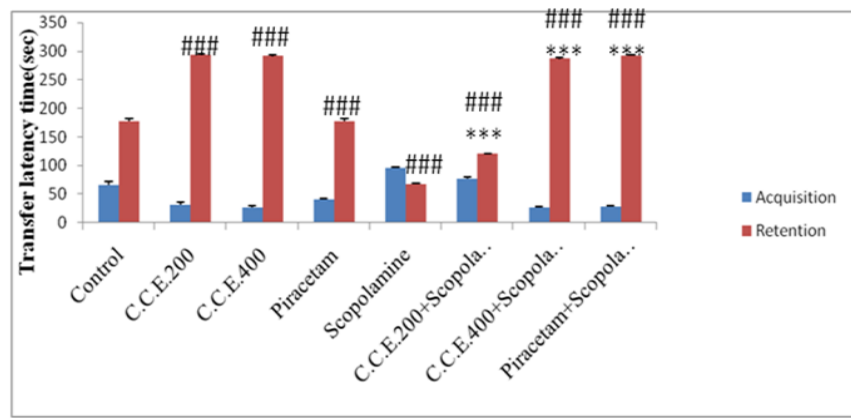

Fig. 2: Effect of Cressa cretica on Passive avoidance apparatus

Results were expressed as MEAN \pm S.E.M., $\mathrm{n}=6$ and analyzed by one-way ANOVA followed by Tukey's test. \#\#\# p $<0.001$ when group compared with control group. $* * * p<0.001$, when groups compared with Scopolamine group.

Transfer latency (TL) of first day reflected learning behavior of animals whereas, TL of second day reflected retention of information or memory. Cressa cretica (200 and $400 \mathrm{mg} / \mathrm{kg}$ ) and 
Piracetam $(200 \mathrm{mg} / \mathrm{kg})$ administration for 28 successive days orally, intra-peritoneally respectively, significantly increased TL on first day as well as second days, indicating significant improvement of learning and memory. Scopolamine $(1 \mathrm{mg} / \mathrm{kg})$ injected before training impaired learning significantly as indicated by decreased TL. Ethanolic extract of Cressa cretica (200 and 400 $\mathrm{mg} / \mathrm{kg})$ and Piracetam $(200 \mathrm{mg} / \mathrm{kg})$ administered orally for 28 days protected the animals from scopolamine-induced impairment in learning and memory.

\subsection{Effect on whole brain Acetylcholinesterase levels}

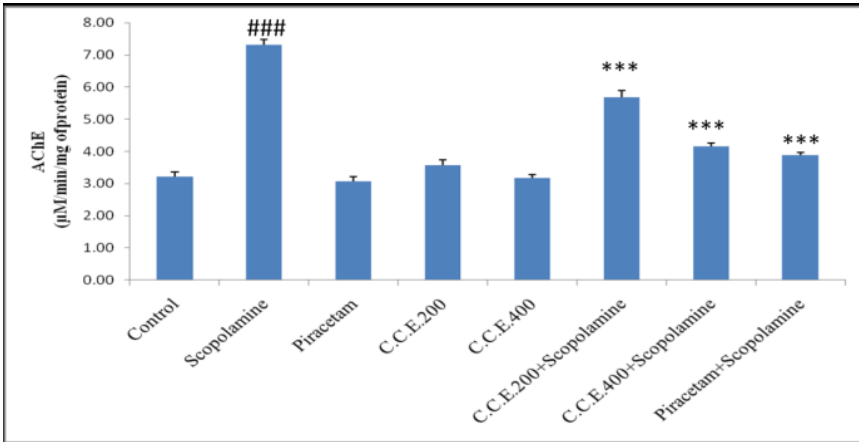

Fig. 3: Effect of ethanolic extract of Cressa cretica on AChE level

Results were expressed as MEAN \pm S.E.M., $\mathrm{n}=6$ and analyzed by one-way ANOVA followed by Dunnett's test. \#\#\# $p<0.001$ when group compared with control group. $* * * p<0.001$, when groups compared with Scopolamine group.

\section{Discussion}

Alzheimer's disease is a genetically heterogeneous neurodegenerative disorder, which is slow in onset but relentless in progress. It is characterized by aphasia, apraxia and agnosia with the loss of memory as the main symptom. Despite the severity and prevalence of this disease, allopathic system of medicine is yet to provide a satisfactory drug. Therefore, we were motivated to explore the potential of medicinal plants to manage this deadly disease. In the present study CCE extract administered orally for 28 days improved learning and memory of mice significantly in both the exteroceptive behavioral models employed. The stimulus lie outside the body in exteroceptive behavior models, whereas, it lies within the body in the case of interoceptive models. In present study the higher dose $400 \mathrm{mg} / \mathrm{kg}$ significantly improved the memory of mice as reflected by diminished TL and enhanced SDL values as compared to control animals. Additionally, CCE (400 $\mathrm{mg} / \mathrm{kg}$ ) reduced central cholinesterase activity. Furthermore, pretreatment with CCE for 28 days protected the animals from memory deficits produced by scopolamine. These findings suggest the possible neuroprotective role for Cressa cretica.

Oxygen free radicals are implicated in the process of age related decline in cognitive performance might be responsible for the development of Alzheimer's disease in elderly persons. Cressa cretica has been reported to possess antioxidant property as well. The neuroprotective effect of CCE may be attributed to its antioxidant property by the virtue of which susceptible brain cells get exposed to less oxidative stress resulting in reduced brain damage and improved neuronal function. The symptoms of dementia are presumed to be related to impaired neurotransmission and degeneration of neuronal circuits in the affected brain areas. Cognitive deterioration occurring in patients with probably $\mathrm{AD}$ is associated with progressive loss of cholinergic neurons and consequent decline in levels of acetylcholine in brain. In present study, CCE significantly decreased the $\mathrm{AChE}$ levels in the mice whole brain homogenate, indicating its potential in the attenuations of severity of AD.
The plant of Cressa cretica contains flavonoids which may be responsible for memory enhancing activity.

\section{Conclusion}

From the results it can be concluded that ethanolic extract of plant of Cressa cretica at a dose of $400 \mathrm{mg} / \mathrm{kg}$ possess nootropic activity which is comparable to Piracetam. Cressa cretica pre-treatment significantly prevented the rise in AChE levels suggesting that it attenuates the excessive formation of reactive oxygen species (ROS). This is in agreement with the observations that Cressa cretica possesses significant nootropic activity.

\section{Acknowledgement}

We are thankful to the Department of Pharmaceutical Technology, Meerut Institute of Engineering and Technology (M.I.E.T.), Meerut for providing chemicals and other infrastructure for doing this research work. The work is dedicated to all my teachers.

\section{References}

[1] Chaudhary S, Khosa RL, Priyank \& Rani S (2012), A report on Pharmacognostical and quality control parameters of stem and root of Cressa cretica Linn, Convolvulaceae. Journal of Pharmacy Research 5(1) 616-621.

[2] Chaudhary S \& Khosa RL (2010), Evaluation of antidiabetic activity of Cressa cretica Linn in alloxan induced diabetes in rats. Pharmacologyonline 31, 81-188.

[3] Dhingra D, Parle M \& Kulkarni SK (2004), Memory enhancing activity of Glycyrrhiza glabra in mice. Journal of Ethnopharmacology 91, 361-365.

[4] Gupta RS \& Kachhawa JBS (2006), Effect of Cressa cretica Linn. methanolic extract on testicular function of albino rats. Pharmaceutical Biology 44(5), 382-88.

[5] Kulkarni PD, Ghaisas MM, Chivatbe ND \& Sankpal PS (2011), Memory enhancing activity of Cissampelos pariera in mice. International Journal of Pharmacy and Pharmaceutical Sciences 3, 206-211.

[6] Papandreou MA, Tsachaki M, Efthimiopoulos S, Cordopatis P, Lamari FN \& Margarity M (2011), Memory enhancing effects of saffron in aged mice is correlated with antioxidant protection. Behavioural Brain Research 219, 197-204.

[7] Priyashree S, Jha S \& Pattanayak SP (2012), Bronchodilatory and mast cell stabilising activity of Cressa cretica L.: evaluation through in vivo and in vitro experimental models. Asian Pac J Trop Med. 5(3), 180-6.

[8] Rani S, Chaudhary S, Singh P, Mishra G, Jha KK \& Khosa RL (2011), Cressa Cretica Linn: An Important Medicinal Plant-A Review on Its Traditional Uses, Phytochemical and Pharmacological Properties. Journal of Natural Product and Plant Resources 1(1), 91-100.

[9] Shahat AA \& Nazif MN (2005), Flavonoids from Cressa cretica, Qatar University.Science.Journal, 25, 72-77.

[10]Suganthi G, Sripathy SK \& Manian K (2008), HPTLC and Antibacterial analysis of extracts of Cressa cretica Linn. Ancient Science of Life 27(3), 1-14.

[11]Sunita P, Jha S \& Pattanayak SP (2011), Anti-inflammatory and Invivo Antioxidant Activities of Cressa cretica Linn, a Halophytic Plant. Middle-East Journal of Scientific Research 8(1), 129-140.

[12] Sunita P, Jha S \& Pattanayak SP (2009), In-vitro Antitussive Activity of Cressa cretica Linn. Using Cough Model in Rodents. Pharmacognosy Research 1, 3, 152-156.

[13]Xu J, Rong S, Xie B, Sun Z, Zhang L, Wu H, Yao P, Zhang X, Zhang Y \& Liu L (2009), Rejuvenation of antioxidant and cholinergic systems contributes to the effect of procyanidins extracted from the lotus seedpod ameliorating memory impairment in cognitively impaired aged rats. European Neuropsychopharmacology 19, 851-860. 